\title{
Severe cutaneous adverse drug reactions of Chinese inpatients: a meta-analysis ${ }^{*}$
}

\author{
Qiancheng Deng ${ }^{1}$ \\ Qinghai Zeng ${ }^{1}$ \\ Chen Jing ${ }^{1}$
}

\author{
Xia Fang ${ }^{1}$ \\ Jianyun $\mathrm{Lu}^{1}$ \\ Jinhua Huang ${ }^{1}$
}

DOI: http:/ /dx.doi.org/10.1590/abd1806-4841.20175171

\begin{abstract}
BACKGROUND: The rate of severe cutaneous adverse drug reactions is low, and these reactions can result in death or disability. An evidence-based epidemiological study of severe cutaneous adverse drug reactions in China has not been reported. Овјестіve: The aim of this study was to analyze epidemiology and characteristics of severe cutaneous adverse drug reactions of Chinese inpatients during the recent 15 years with meta-analysis.

METHODS: We retrospectively reviewed Chinese literature reporting severe cutaneous adverse drug reactions and collecting data from 2000 to 2015, which were in accordance with our inclusion criteria. All included data were analyzed with the Launch Open Meta-Analyst software.

RESULTS: Twenty-five articles involving 928 cases with severe cutaneous adverse drug reactions were included. Men to women ratio was 1.14:1. Twenty-one per cent of the patients had drug allergy history. Antibiotics (26.0\%), sedative hypnotics and anticonvulsants $(21.6 \%)$, and antipyretic analgesics $(17.1 \%)$ were the most common causative drugs. The most frequent clinical subtype was Stevens-Johnson syndrome (50.1\%), followed by toxic epidermal necrolysis (25.4\%), exfoliative dermatitis $(21.0 \%)$ and drug-induced hypersensitivity syndrome (1.6\%). In addition to skin rashes, patients with severe cutaneous adverse drug reactions suffered mostly from fever (73\%), and blood routine abnormality $(66.7 \%)$.

STUDY LIMITATIONS: This meta-analysis is limited by its retrospective design and by its methodological variation.

CONCLUSION: The most common causative drugs were antibiotics and sedative hypnotics and anticonvulsants. Stevens-Johnson syndrome was the most frequent clinical subtype of severe cutaneous adverse drug reactions. In addition to skin rashes, patients with severe cutaneous adverse drug reactions suffered mostly from fever, mucosal lesion, and hematologic abnormalities.
\end{abstract}

Keywords: Drug eruptions; Meta-analysis; Dermatitis

\section{INTRODUCTION}

Adverse cutaneous drug reactions (ACDRs) are the most frequent adverse events resulting from drug treatment. Studies have shown that up to $6.7 \%$ of hospitalized patients present some degree of ACDR, with severe forms ranging from $0.33 \%$ to $3 \% \cdot{ }^{1-3}$ Although the rate of severe cutaneous adverse drug reaction (SCADRs) is low, these reactions can affect anyone who takes medications and can result in death or disability. ${ }^{4}$

The World Health Organization defines SCARDs are those requiring hospitalization or that extend the length of hospital stay, resulting in persistent or significant disability or life-threatening. ${ }^{3}$ The spectrum of SCADRs includes Stevens-Johnson syndrome (SJS), toxic epidermal necrolysis (TEN), and drug-induced hypersensitivity syndrome (DIHS)/ Drug rash with eosinophilia and systemic symptoms (DRESS). ${ }^{5}$ DIHS is a new type of adverse drug reaction (ADR) and is considered a SCADR. In China, exfoliative dermatitis (ED) is also classified as SCADR. ${ }^{6}$

During the past 15 years, numerous studies regarding SCADRs have been reported in China. However, there were incon- sistent results and insufficient statistical power. Moreover, it is very important to acquire knowledge on SCARDs for their great impact on morbidity and mortality rates, and on hospital costs. These reasons motivated us to carry out this study to explore the characteristics of SCADRs of Chinese inpatients.

\section{METHODS}

\section{Selection}

Electronic databases were searched using the following key words: severe cutaneous adverse drug reactions / severe drug eruptions / severe dermatitis medicamentosa, causative drugs, clinical subtypes, meta-analysis. Databases used were Chinese National Knowledge Infrastructure, Wan Fang Med Online, Chinese Biology Medical Literature Database and VIP Database. The reference sections of all retrieved articles were manually searched for additional studies.

\section{Inclusion criteria}

The following criteria were used: (1) The study objects were the Chinese inpatients with severe drug eruptions; (2) All the arti-

\footnotetext{
Received on 23.09.2015

Approved by the Advisory Board and accepted for publication on 16.05.2016

* Study conducted at the Department of Dermatology, Third Xiangya Hospital, Central South University - Changsha, China.

Financial support: None.

Conflict of interest: None.

1 Department of Dermatology, Third Xiangya Hospital, Central South University - Changsha, China.

(C)2017 by Anais Brasileiros de Dermatologia
} 
cles were included from the Chinese core journals, the Chinese core journals of science and technology, or the dissertations; (3) Data sources between 2000-2015 were included; (4) The latest article was selected on condition that the identical data sets were published in different journals; (5) The data of gender, history of drug allergy, causative drugs, clinical subtypes, physical examinations, or laboratory examinations were complete. According to inclusion criteria, two investigators independently scrutinized all articles and screened standard articles.

\section{Data extraction}

To test for reliability of our extraction process, two investigators independently extracted data of the included articles. We extracted data of total number of the patients, the number of men and women, history of drug allergy, causative drugs, clinical subtypes, relation between causative drugs and clinical subtypes, physical and laboratory examinations. Other information extracted included first author, publication year of the articles, name of standard journal or dissertations in each study.

\section{Statistical analysis}

The Launch Open Meta Analyst was used to analyze all included studies. The effect size (ES), 95\% confidence intervals (CI), and $\mathrm{P}$ value were calculated. Heterogeneity of studies was examined by the inconsistency index $\left(\mathrm{I}^{2}\right)$ test. According to the inconsistency index, the random-effect model and the fixed-effect model were chosen. If a statistical difference existed in terms of heteroge- neity $\left(\mathrm{I}^{2}>50 \%\right)$, a random effect model was adopted as the analysis method. Otherwise, a fixed-effect model was used.

\section{RESULTS}

\section{Literature retrieval}

According to our criteria, 2425 articles were retrieved. Five hundred articles of obvious irrelevance were excluded. There were 1825 excluded articles that were reviewed, but were not included because they were case report, single clinical subtype, single causative drug study or duplicated publication after screening the articles. In addition, 75 articles were excluded (not published in the last 15 years and data sources before 2000, not core journals, or had insufficient data). Finally, 25 articles were included in our meta-analysis. Features of these 25 studies are presented in table 1. ${ }^{7-31}$

\section{Results of meta-analysis \\ Gender proportion}

Twenty-five studies reported the gender of patients. There were 928 patients, comprising 495 men and 433 women. The proportion of men was $53.2 \%$ [ $\mathrm{I}^{2}=56 \%, 95 \% \mathrm{CI}(0.484$ to 0.581$\left.), \mathrm{P}<0.001\right]$. The proportion of women was $46.8 \%\left[\mathrm{I}^{2}=56 \%, 95 \% \mathrm{CI}\right.$ ( 0.419 to 0.516 ), $\mathrm{P}<0.001]$. The man to woman ratio was 1.14:1.

\section{History of drug allergy}

There were 13 articles analyzing drug allergy history. The proportion of drug allergy history was $21.3 \%\left[I^{2}=79 \%, 95 \% \mathrm{CI}(0.136\right.$ to 0.290 ), $\mathrm{P}<0.001$ ] (Figure 1).

\begin{tabular}{|c|c|c|c|c|c|c|c|c|c|c|}
\hline \multirow[t]{2}{*}{ Study } & \multirow[t]{2}{*}{ Year } & \multirow[t]{2}{*}{ Cases } & \multicolumn{2}{|c|}{ Gender } & \multirow{2}{*}{$\begin{array}{l}\text { Age } \\
\text { (Year) }\end{array}$} & \multirow[t]{2}{*}{ Region } & \multirow[t]{2}{*}{$\mathrm{CD}$} & \multirow[t]{2}{*}{ CS } & \multirow[t]{2}{*}{$\mathbf{R}$} & \multirow[t]{2}{*}{ PLE } \\
\hline & & & Male & Female & & & & & & \\
\hline $\mathrm{Li}^{7}$ & 2014 & 23 & 11 & 12 & $4-82$ & East & $\mathrm{D}$ & $\mathrm{D}$ & $\mathrm{N}$ & $\mathrm{N}$ \\
\hline Yang $^{8}$ & 2013 & 32 & 15 & 17 & $1.5-80$ & Central China & $\mathrm{D}$ & $\mathrm{D}$ & $\mathrm{N}$ & $\mathrm{N}$ \\
\hline $\mathrm{Li}^{9}$ & 2013 & 42 & 29 & 13 & $6-74$ & South & $\mathrm{D}$ & $\mathrm{D}$ & $\mathrm{Y}$ & $\mathrm{Y}$ \\
\hline $\operatorname{Sun}^{10}$ & 2013 & 29 & 17 & 12 & $5-12$ & East & $\mathrm{D}$ & $\mathrm{D}$ & $\mathrm{N}$ & $\mathrm{Y}$ \\
\hline Fang $^{11}$ & 2012 & 51 & 32 & 19 & $3 m-14.5$ & Southwest & $\mathrm{D}$ & $\mathrm{D}$ & $\mathrm{N}$ & $\mathrm{N}$ \\
\hline $\mathrm{Ji}^{12}$ & 2012 & 46 & 22 & 24 & $13-81$ & East & $\mathrm{D}$ & $\mathrm{D}$ & $\mathrm{Y}$ & $\mathrm{Y}$ \\
\hline $\mathrm{Su}^{13}$ & 2012 & 28 & 16 & 12 & $5-68$ & North & $\mathrm{D}$ & $\mathrm{D}$ & $\mathrm{N}$ & $\mathrm{Y}$ \\
\hline Wei ${ }^{14}$ & 2012 & 76 & 45 & 31 & $6-73$ & North & $\mathrm{D}$ & $\mathrm{D}$ & $\mathrm{Y}$ & $\mathrm{Y}$ \\
\hline $\mathrm{Liu}^{15}$ & 2012 & 82 & 38 & 44 & $15-68$ & North & $\mathrm{D}$ & $\mathrm{D}$ & $\mathrm{N}$ & $\mathrm{Y}$ \\
\hline Chen $^{16}$ & 2011 & 62 & 21 & 41 & $11-70$ & North & $\mathrm{D}$ & $\mathrm{D}$ & $\mathrm{Y}$ & $\mathrm{Y}$ \\
\hline Wang $^{17}$ & 2010 & 38 & 27 & 11 & $20-79$ & Central China & $\mathrm{D}$ & $\mathrm{D}$ & $\mathrm{Y}$ & $\mathrm{Y}$ \\
\hline $\mathrm{Liu}^{18}$ & 2010 & 44 & 23 & 21 & $11-76$ & North & $\mathrm{D}$ & $\mathrm{D}$ & $\mathrm{N}$ & $\mathrm{Y}$ \\
\hline Kang $^{19}$ & 2009 & 25 & 14 & 11 & $6 m-16$ & Northwest & $\mathrm{D}$ & $\mathrm{D}$ & $\mathrm{Y}$ & $\mathrm{Y}$ \\
\hline $\mathrm{Luo}^{20}$ & 2009 & 33 & 12 & 21 & $60-83$ & South & $\mathrm{D}$ & $\mathrm{D}$ & $\mathrm{N}$ & $\mathrm{Y}$ \\
\hline Zhang $^{21}$ & 2008 & 24 & 8 & 16 & $5-67$ & Central China & $\mathrm{D}$ & $\mathrm{D}$ & $\mathrm{N}$ & $\mathrm{Y}$ \\
\hline $\mathrm{Zhu}^{22}$ & 2008 & 74 & 48 & 26 & $12-87$ & East & $\mathrm{D}$ & $\mathrm{D}$ & $\mathrm{N}$ & $\mathrm{Y}$ \\
\hline $\mathrm{Luo}^{23}$ & 2008 & 24 & 10 & 14 & $6 m-8$ & South & $\mathrm{D}$ & $\mathrm{D}$ & $\mathrm{N}$ & $\mathrm{Y}$ \\
\hline Wang ${ }^{24}$ & 2007 & 19 & 13 & 6 & $9-78$ & Central China & $\mathrm{D}$ & $\mathrm{D}$ & $\mathrm{N}$ & $\mathrm{Y}$ \\
\hline Zou $^{25}$ & 2007 & 31 & 19 & 12 & $1-71$ & Central China & $\mathrm{D}$ & $\mathrm{D}$ & $\mathrm{N}$ & $\mathrm{Y}$ \\
\hline $\mathrm{Miao}^{26}$ & 2006 & 22 & 15 & 7 & $4-91$ & Central China & $\mathrm{D}$ & $\mathrm{D}$ & $\mathrm{Y}$ & $\mathrm{Y}$ \\
\hline $\mathrm{Hu}^{27}$ & 2006 & 24 & 8 & 16 & $33-82$ & East & $\mathrm{D}$ & $\mathrm{D}$ & $\mathrm{Y}$ & $\mathrm{Y}$ \\
\hline $\mathrm{Xu}^{28}$ & 2006 & 29 & 17 & 12 & $15-79$ & East & $\mathrm{D}$ & $\mathrm{D}$ & $\mathrm{Y}$ & $\mathrm{Y}$ \\
\hline Chen $^{29}$ & 2005 & 24 & 9 & 15 & $15-54$ & Northeast & $\mathrm{D}$ & $\mathrm{D}$ & $\mathrm{Y}$ & $\mathrm{Y}$ \\
\hline $\mathrm{Xiao}^{30}$ & 2004 & 22 & 13 & 9 & $1-17$ & Southwest & $\mathrm{D}$ & $\mathrm{D}$ & $\mathrm{Y}$ & $\mathrm{Y}$ \\
\hline Fang $^{31}$ & 2004 & 24 & 13 & 11 & $12-84$ & Southwest & $\mathrm{D}$ & $\mathrm{D}$ & $\mathrm{Y}$ & $\mathrm{N}$ \\
\hline
\end{tabular}

$\mathrm{CD}=$ Causative drug, $\mathrm{CS}=$ clinical sub-types, $\mathrm{R}=$ Relationship between causative drug and clinical sub-types, $\mathrm{PLE}=$ Physical and laboratory examinations, $\mathrm{D}=\mathrm{Detailed}$ data, $\mathrm{Y}=\mathrm{Mentioned}$, $\mathrm{N}=$ Not mentioned. 


\section{Causative drugs}

Twenty-five articles described causative drugs in detail. As presented in Figure 2, antibiotics (29.2\%), sedative hypnotics and anticonvulsants (SHA) (26.0\%), and antipyretic analgesics (AA) $17.1 \%$ were the most common causative drug groups. Gout suppressants (GS) were responsible for $11.0 \%$. Chinese medicine and Chinese patent medicine (CMCPM) was implicated in $2.2 \%$, others in $2.1 \%$, unknown drugs (UD) in $1.7 \%$, unconfirmed drugs (UCD) in $1.5 \%$ and biological agents (BA) in $1.4 \%$.

\section{Clinical subtypes}

Clinical subtypes of SCADRs were analyzed in 25 articles. As shown in Figure 3, the most frequent clinical type of SCADRs was SJS (50.1\%), followed by TEN 25.4\% and ED 21.0\%. However, the proportion of DIHS was only $1.6 \%$.

Relation between causative drugs and clinical subtypes

There were 12 studies exposing the relation between causative drugs and clinical subtypes. Causative drugs of SCADRs and their major clinical subtypes are presented in table 2. Clinical subtypes of SCADRs and their most frequent causative drugs are shown in Table 3.

\section{Physical and laboratory examinations}

As shown in Figure 4, fever was implicated in $73.0 \%$ of cases; $63.8 \%$ of the patients had mucosal lesions (ML) (given the insufficiency of other data of physical examinations, such as edema, lymphadenomegaly, etc., only fever and ML were analyzed). Blood routine abnormality (BRA) was presented in $66.7 \%$. The incidence of liver dysfunction (LD) was $41.8 \%$, urinalysis abnormality (UA) $32.5 \%$. Electrolyte imbalance (EI) was presented in $29.5 \%$ of the patients, renal dysfunction (RD) in $16.8 \%$, cardiac enzymes abnormality (CEA) in $15.2 \%$ and stool routine abnormality (SRA) in $8.4 \%$.

\section{Publication bias}

In this meta-analysis, there was no significant publication bias for gender proportion, history of drug allergy, physical and laboratory examinations. However, possible publication bias may exist for causative drugs, clinical subtypes, relation between causative drugs and clinical subtypes. Publication bias is derived from exclu- sion of results that were not published. We specifically acknowledge the limitations and expect more studies. Nevertheless, a possible publication bias does not affect the main results.

\section{Influence analysis}

Influence analysis was performed to investigate the influence of a single study on the overall analysis. The heterogeneities were not changed significantly after exclusion of any single study. Furthermore, the corresponding pooled standardized mean difference (SMD) and 95\% CI were not conspicuously altered with any single study excluded. Therefore, the reliability of the results was enhanced by the influence analysis.

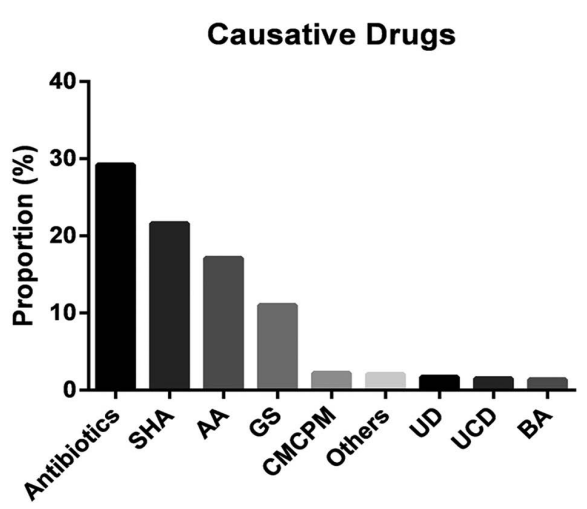

Figure 2: Proportions of causative drugs of severe cutaneous adverse drug reactions. The meta-analysis included 928 patients. As the figure shows, the proportion of antibiotics was $29.2 \%$ [I $2=76 \%$, $95 \% \mathrm{CI}(0.235$ to 0.348$), \mathrm{P}<0.001]$, sedative hypnotics and anticonvulsants (SHA) $21.6 \%$ [ $\mathrm{I} 2=81 \%, 95 \% \mathrm{CI}$ ( 0.163 to 0.268$), \mathrm{P}<0.001$, antipyretic analgesics (AA) $17.1 \%$ [I2 $=65 \%, 95 \% \mathrm{CI}(0.171$ to 0.210$)$, $\mathrm{P}<0.001]$, gout suppressants (GS) $11.0 \%$ [I2=81\%, 95\% CI $(0.077$ to $0.143), \mathrm{P}<0.001]$, Chinese medicine and Chinese patent medicine (CMCPM) $2.2 \%$ [I2=0\%, 95\% CI (0.013 to 0.032$), \mathrm{P}=0.663]$, others $2.1 \%$ [I $=0 \%, 95 \% \mathrm{CI}(0.012$ to 0.030$), \mathrm{P}=0.607]$, unknown drugs (UD) $1.7 \%$ [I2 $=4 \%, 95 \% \mathrm{CI}(0.009$ to 0.025$), \mathrm{P}=0.411]$, unconfirmed drugs (UCD) $1.5 \%$ [I2=3\%, 95\% CI (0.009 to 0.025$), \mathrm{P}=0.411]$ and biological agents (BA) $1.4 \%$ [I2=19\%, $95 \% \mathrm{CI}(0.007$ to 0.143$), \mathrm{P}=0.201]$

\section{Studies}

10-Sun 2013

37-Fang 2012

22-Ji 2012

32-Su 2012

58-Wang 2010

83-Kang 2009

91-Zhang 2008

113-Wang 2007

112-Zou 2007

135-Miao 2006

136-Hu 2006

121-Xu 2006

164-Chen 2005

Overall (I^2=79\%, P<0.001)
Estimate $(95 \%$ C.I. $)$

$0.207(0.059,0.354)$

$0.059(0.000,0.123)$

$0.348(0.210,0.485)$

$0.500(0.315,0.685)$

$0.263(0.123,0.403)$

$0.080(0.000,0.186)$

$0.083(0.000,0,194)$

$0.158(0.000,0.322)$

$0.290(0.131,0.450)$

$0.273(0.087,0.459)$

$0.042(0.000,0.122)$

$0.448(0.267,0.629)$

$0.208(0.046,0.371)$

$0.213(0.136,0.290)$
EV/ Trt

$6 / 29$

$3 / 51$

$16 / 46$

$14 / 28$

$10 / 38$

$2 / 25$

$2 / 24$

$3 / 19$

$9 / 31$

$6 / 22$

$1 / 24$

$13 / 29$

$5 / 24$

$90 / 390$

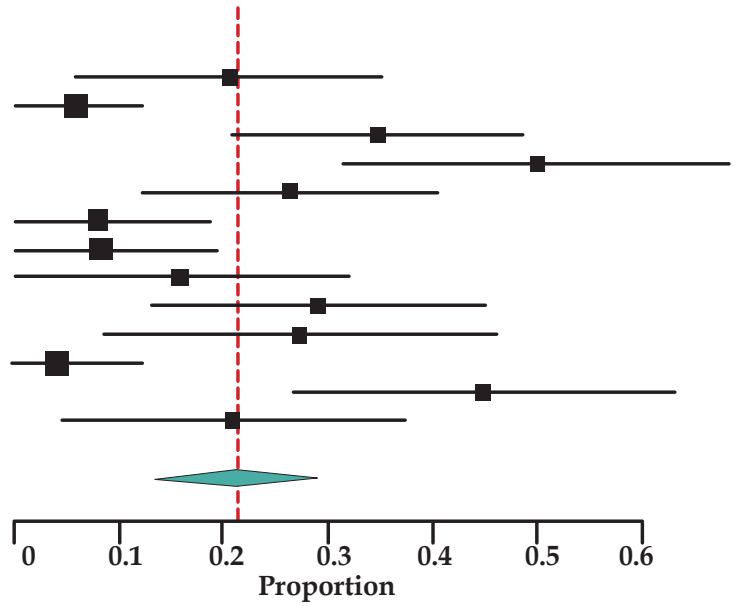

Proportion

Figure 1: Forest plot of drug allergy history. The meta-analysis showed $21.3 \%$ of the patients had drug allergy history. [I2=79\%, $95 \% \mathrm{CI}(0.136$ to 0.290$), \mathrm{P}<0.001$ ]. 


\section{DISCUSSION}

Epidemiology of SCADRs has been reported in multiple countries and regions. ${ }^{32-34}$ However, to our knowledge, an epidemiological study of Chinese inpatients with SCADRs has not been reported. This meta-analysis is the first to respectively analyze epidemiology and clinical characteristics of SCADRs among Chinese inpatients during the recent 15 years.

In this meta-analysis, men predominance was found in Chinese inpatients with SCADRs, coincident with previous studies. $5,35,36$ This study also demonstrated that $21.3 \%$ of the patients had a history of drug allergy. People with a history of drug allergy may present a defect of detoxification function, which makes them more vulnerable to suffer drug eruptions.

Similar to previous studies, this meta-analysis manifested antibiotics $(29.2 \%)$ were the most frequent causative drugs for SCADRs, followed by SHA $(26.0 \%))^{5,36-38}$ AA were implicated in $17.1 \%$ of the patients. Inconsistently, some studies reported antibiotics and allopurinol were the most common culprit drugs. ${ }^{32,39}$ It is

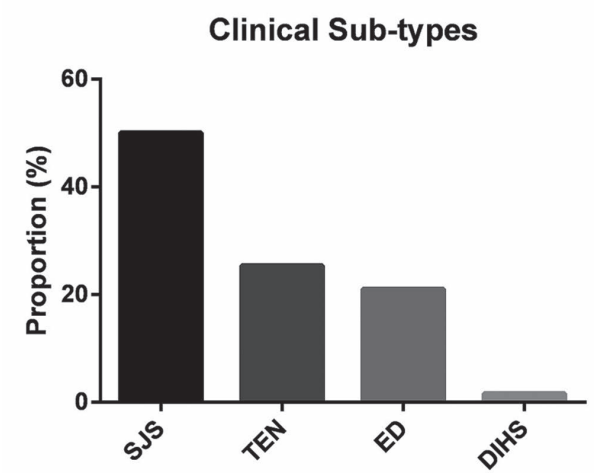

Figure 3: Proportions of clinical sub-types of severe cutaneous adverse drug reactions. The meta-analysis included 928 patients. As the figure shows, the most frequent clinical sub-type was Stevens-Johnson syndrome (SJS) $(50.1 \%)[\mathrm{I} 2=84 \%, 95 \% \mathrm{CI}(0.425$ to $0.577), \mathrm{P}<0.001]$, followed by toxic epidermal necrolysis (TEN) (25.4\%) [I2=74\%, 95\% CI $(0.202$ to 0.306$), \mathrm{P}<0.001]$, then exfoliative dermatitis (ED) (21.0\%) [I2=82\%, 95\% CI (0.156 to 0.264$), \mathrm{P}<0.001]$. The proportion of drug-induced hypersensitivity syndrome (DIHS) was $1.6 \%$ [I2=0\%, 95\% CI (0.008 to 0.024$), \mathrm{P}=0.799]$

\section{TABLE 2: Causative drugs and their clinical sub-types}

\begin{tabular}{|c|c|c|c|c|}
\hline \multirow{2}{*}{$\begin{array}{l}\text { Causative } \\
\text { drugs }\end{array}$} & \multicolumn{3}{|c|}{ Clinical sub-types } & \multirow[b]{2}{*}{ DIHS (9.9\%) } \\
\hline & SJS (40.7\%) & ED (25.7\%) & TEN (25.4\%) & \\
\hline $\mathrm{AA}$ & SJS (53.0\%) & TEN (23.7\%) & DIHS (16.4\%) & $\operatorname{ED}(8.5 \%)$ \\
\hline SHA & SJS (38.4\%) & TEN $(35.6 \%)$ & DIHS $(24.3 \%)$ & $\operatorname{ED}(15.2 \%)$ \\
\hline GS & SJS (42.4\%) & $\operatorname{ED}(23.7 \%)$ & TEN $(20.9 \%)$ & DIHS $(6.7 \%)$ \\
\hline СМСРM & SJS $(56.3 \%)$ & $\operatorname{ED}(39.0 \%)$ & TEN (27.1\%) & \\
\hline BA & SJS (40.8\%) & TEN (40.6\%) & DIHS $(20.6 \%)$ & $\operatorname{ED}(4.9 \%)$ \\
\hline UD & $\operatorname{TEN}(46.1 \%)$ & SJS $(46.1 \%)$ & & \\
\hline UCD & TEN (63.8\%) & SJS (25.8\%) & ED (23.1\%) & DIHS (14.1\%) \\
\hline Others & $\mathrm{ED}(52.6 \%)$ & $\operatorname{TEN}(31.6 \%)$ & SJS $(23.4 \%)$ & \\
\hline
\end{tabular}

SJS=Stevens Johnson syndrome, ED=Exfoliative dermatitis, TEN= Toxic epiderma necrolysis, DIHS=Drug-induced hypersensitivity syndrome, AA=antipyretic analgesics, $\mathrm{SHA}=$ sedative hypnotics and anticonvulsants, GS=gout suppressants, $\mathrm{CMCPM}=$ Chinese medicine and Chinese patent medicine, $\mathrm{BA}=$ biological agents, $\mathrm{UD}=$ unknown drugs, and $\mathrm{UCD}=$ unconfirmed drugs. noteworthy that CMCPM accounted for $2.2 \%$. CMCPM is commonly used in China. Given that CMCPM are very complex, it is difficult to identify the culprit ingredient in the medicine.

Our study showed SJS (50.1\%) was the most common clinical subtype for SCADRs, followed by TEN (25.4\%), which was consistent with most studies. ${ }^{1,5,32}$ Interestingly, Grando et al. analyzed SCADRs and pointed to the predominance of DIHS. DIHS is a new type of SCADRs that accounted for $1.6 \%$ in this study. ${ }^{3}$ This result may be associated with the insufficient knowledge on DIHS for many Chinese dermatologists.

Antibiotics, the prominent causative drugs, were responsible for $40.7 \%$ of SJS, $25.7 \%$ of ED and $25.4 \%$ of TEN cases. SHA, another common culprit drugs, were implicated in $38.4 \%$ of SJS, $35.6 \%$ of TEN, $24.3 \%$ of DIHS. (Table 2) Besides, our study demonstrated that antibiotics and AA were major causes of SJS. In addition to antibiotics, SHA were the main culprit drugs for TEN (Table 3).

SCADRs may affect multiple organs and present with other systemic symptoms. In a previous study, $85.7 \%$ of patients developed hepatitis, $65.7 \%$ fever, $54.3 \%$ leukocytosis, and $31.4 \%$ developed acute renal insufficiency. Su et al. reported that transaminitis (37.5\%) and gastrointestinal manifestations (25\%) were the most common complications. ${ }^{32}$ This pooled estimate revealed $73.0 \%$ and $63.8 \%$ of the patients suffered from fever and mucosal lesions, respectively. Blood routine abnormality $(66.7 \%)$ and liver dysfunction (41.8\%) were most frequent abnormal examinations in laboratory investigations.

\section{CONCLUSION}

This meta-analysis is the first to retrospectively analyze the epidemiology and characteristics of SCADRs among Chinese inpatients during the recent 15 years. Men were slightly more af-

\section{Physical and Laboratory Examinations}

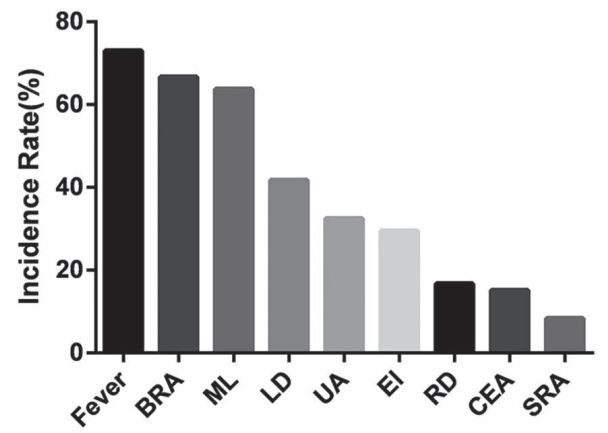

FiguRE 4: Incidence rate of physical and laboratory examinations. As shown in figure, fever $(73.0 \%)$ [I2=95\%, 95\%CI (0.645 to 0.816$)$, $\mathrm{P}<0.001]$ and blood routine abnormality (BRA) $(66.7 \%)[\mathrm{I} 2=83 \%$, $95 \% \mathrm{CI}(0.586$ to 0.748$), \mathrm{P}<0.001$ ] were the most frequent clinical features; mucosal lesions (ML) was presented in $63.8 \%$ [I2=91\%, 95\% CI (0.536 to 0.740$), \mathrm{P}<0.001$ ] of the patients and liver dysfunction (LD) in $41.8 \%$ [ $\mathrm{I} 2=82 \%, 95 \% \mathrm{CI}(0.344$ to 0.492$), \mathrm{P}<0.001]$, urinalysis abnormality (UA) in $32.5 \%$ [ $\mathrm{I} 2=81 \%, 95 \% \mathrm{CI}(0.231$ to 0.420$), \mathrm{P}<0.001]$, electrolyte imbalance (EI) in $29.5 \%$ [I2 $=92 \%, 95 \% \mathrm{CI}(0.179$ to 0.412$)$, $\mathrm{P}<0.001]$, renal dysfunction (RD) in $16.8 \%$ [I2=70\%, 95\% CI $(0.120$ to 0.216 ), $\mathrm{P}<0.001$ ], cardiac enzymes abnormality (CEA) in $15.2 \%$ [I2 $=85 \%, 95 \% \mathrm{CI}(0.083$ to 0.221$), \mathrm{P}<0.001]$, stool routine abnormality (SRA) was $8.4 \%$ [I2=22\%, 95\% CI (0.056 to 0.112), $\mathrm{P}=0.232]$ 


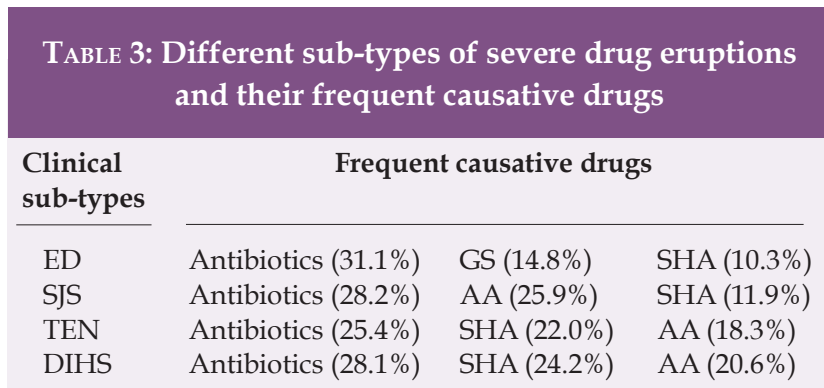

$\mathrm{ED}=$ Exfoliative dermatitis, GS=gout suppressants, $\mathrm{SHA}=$ sedative hypnotics and anticonvulsants, SJS=Stevens Johnson syndrome, AA=antipyretic analgesics, TEN= Toxic Epidermal Necrolysis, DIHS=Drug-induced hypersensitivity syndrome

\section{REFERENCES}

1. Lazarou J, Pomeranz BH, Corey PN. Incidence of adverse drug reactions in hospitalized patients: a meta-analysis of prospective studies. JAMA. 1998;279:1200-5.

2. Zaraa I, Jones M, Trojjet S, Cheikh Rouhou R, El Euch D, Mokni M, et al. Severe adverse cutaneous drug eruptions: epidemiological and clinical features. Int $\mathrm{J}$ Dermatol. 2011;50:877-80.

3. Grando LR, Schmitt TA, Bakos RM. Severe cutaneous reactions to drugs in the setting of a general hospital. An Bras Dermatol. 2014;89:758-62.

4. Roujeau JC, Stern RS. Severe adverse cutaneous reactions to drugs. N Engl J Med. 1994;331:1272-85.

5. Li LF, Ma C. Epidemiological study of severe cutaneous adverse drug reactions in a city district of China. Clin Exp Dermatol. $2006 ; 31: 642-7$.

6. Ghislain PD, Roujeau JC. Treatment of severe drug reactions: Stevens-Johnson syndrome, toxic epidermal necrolysis and hypersensitivity syndrome. Dermatol Online J. 2002:8:5.

7. Li P. Retrospective Analysis of Clinical Features, Sensitization Drugs and Prognosis Related Factors of Severe Drug Eruption. China Medical Herald. 2014;11:118-20.

8. Yang GY, Zhou XY, Su F. A Retrospective Analysis of 32 Cases with Severe Drug Eruption. Chinese Journal of Pharmacoepidemiology. 2013;11:600-2.

9. Li YQ, Xie Z, Chen JL. Clinical analysis of 42 cases with severe drug eruption. Guangxi Medical Journal. 2013:1413-14, 17.

10. Sun WG. Clinical analysis of 29 cases with severe drug eruption in children. Chinese Journal of General Practitioners. 2013;12: 996-7.

11. Fang $X$. Retrospective analysis of 51 cases with severe drug eruption in children [dissertation]. Chongqing: Chongqing Medical University; 2012.

12. Ji MK, Liu Z, Chen LH. Clinical analysis of 46 cases with severe drug eruption. Journal of Clinical Dermatology. 2012;41:634-5.

13. Su WQ. Clinical analysis of 28 cases with severe drug eruption. Chinese Remedies \& Clinics. 2012; 12:512-3.

14. Wei WJ, Qiao SF. Clinical analysis of 76 cases of severe drug eruption. The Chinese Journal of Dermatovenereology. 2012;26:403-4, 37.

15. Liu RR, Zhu H, He CD. Clinical analysis of glucocorticoid with intravenous immunoglobulin to treat severe drug eruption. Journal of Chinese Practical Diagnosis and Therapy. 2012; 7:698-9.

16. Chen XM, Chen LF. Clinical Analysis of 62 cases with severe drug eruption. Chinese Remedies \& Clinics. 2011;11:964-5.

17. Wang XL, Li R, Fang $\mathrm{H}$. Clinical analysis of 38 cases with severe drug eruption. Journal of Practical Dermatology. 2010;3:137-40.

18. Liu JL, Hu B, Zhao ZL. Retrospective study with 44 cases with severe drug eruptions. Chinese Journal of Clinical Healthcare. 2010;13:161-3.

19. Kang XJ, Ju HE, Xu YM. Clinical analysis of 25 cases with severe drug eruption. Chinese Journal of Leprosy Skin Disease. 2009;25:858-9.

20. Luo JY, Chen DH, Huang X. Analysis of 33 cases of aged people with severe drug eruption. The Chinese Journal of Dermatovenereology. 2009;23:90-1.

21. Zhang LF, Zhou FH. Clinical analysis of 24 cases with severe drug eruption. Chinese Journal of Leprosy Skin Disease. 2008;24:276-7.

22. Zhu J. Clinical Analysis of 74 Cases with Severe Drug Eruption. Chinese Journal of Dermatovenerology of Integrated Traditional and Western Medicine. 2008;7:36-7.

23. Luo JY, Huang X, Liu QY. Analysis of 24 Cases of Children With Severe Drug Eruption. The Chinese Journal of Dermatovenereology. 2008;22:729-30. fected than women. Nearly a quarter of the patients had a history of drug allergy. This pooled estimate revealed antibiotics, SHA, and AA was the most frequently drug associated with SCADRs. SJS was the most common clinical pattern, followed by TEN and ED. DIHS only accounted for a very small proportion. In this meta-analysis, more than half patientws were suffered from fever and mucosal lesions. Hematological and hepatic involvements were the two most frequent systemic involvements. $\square$

\section{ACKNOWLEDGMENTS}

We thank to the authors who made detailed data available for this meta-analysis and our colleagues for their hard work.

24. Wang QY. Clinical analysis of 19 cases with severe drug eruption. China Medical Herald. 2007;4:138-9.

25. Zou LY, Liu JX, Fang J. Clinical analysis of 31 cases with severe drug eruption. Journal of Bengbu Medical College. 2007;32:75-6.

26. Miao Q, Yu JB. Clinical analysis of 22 cases with severe drug eruption. Chinese Journal of Leprosy Skin Disease. 2006;22:876-7.

27. Hu C, Wu JH, Gu J. Analysis of 24 Cases of Severe Drug Eruption. The Chinese Journal of Dermatovenereology. 2006;20:680-92.

28. Xu WH, Wu WY, Chen MH. Clinical Analysis of 29 Cases with Severe Drug Eruption. Chinese Journal of Leprosy Skin Disease. 2006; 22: 615-6.

29. Chen YG, Lü L, Chen X. Analysis of 24 cases with severe drug eruption. Chin J Crit Care Med. 2005;5:380.

30. Xiao YZ, Wang H. Clinical analysis of 22 children with severe drug eruption. Journal of Pediatric Pharmacy. 2004;10: 26-7.

31. Fang Q, He Q, Zhao HW. Treatment and Nursing of Severe Drug Eruption. Journa of Nurses Training. 2004;6:543-5.

32. Su P, Aw CW. Severe cutaneous adverse reactions in a local hospital setting: a 5-year retrospective study. Int J Dermatol. 2014;53:1339-45.

33. Hernández-Salazar A, Rosales SP, Rangel-Frausto S, Criollo E, Archer-Dubon C, Orozco-Topete R. Epidemiology of adverse cutaneous drug reactions. A prospective study in hospitalized patients. Arch Med Res. 2006;37:899-902.

34. Wolf R, Orion E, Marcos B, Matz H. Life-threatening acute adverse cutaneous drug reactions. Clin Dermatol. 2005;23:171-81.

35. Pitché P, Padonou CS, Kombate K, Mouzou T, Tchangai-Walla K. Stevens-Johnson syndrome and toxic epidermal necrolysis in Lome (Togo). Evolutional and etiological profiles of 40 cases. Ann Dermatol Venereol. 2005;132:531-4.

36. Schöpf E, Stühmer A, Rzany B, Victor N, Zentgraf R, Kapp JF. Toxic epidermal necrolysis and Stevens-Johnson syndrome. An epidemiologic study from West Germany. Arch Dermatol. 1991;127:839-42.

37. Leenutaphong V, Sivayathorn A, Suthipinittharm P, Sunthonpalin P. StevensJohnson syndrome and toxic epidermal necrolysis in Thailand. Int $\mathrm{J}$ Dermatol. 1993;32:428-31.

38. Roujeau JC, Kelly JP, Naldi L, Rzany B, Stern RS, Anderson T, et al. Medication use and the risk of Stevens-Johnson syndrome or toxic epidermal necrolysis. N Engl J Med. 1995;333:1600-7.

39. Lee HY, Tay LK, Thirumoorthy T, Pang SM. Cutaneous adverse drug reactions in hospitalised patients. Singapore Med J. 2010;51:767-74.
MAILING ADDRESS:
Huang Jinhua
Department of Dermatology,
Third Xiangya Hospital,
Central South University, No. 138,
Tongzipo Road,
Changsha, Hunan 410013, China.
E-mail: huangiinhua60@163.com

How to cite this article: Qiancheng D, Fang X, Qinghai Z, Jianyun L, Jing C, Jinhua H. Severe cutaneous adverse drug reactions of Chinese inpatients: a meta-analysis. An Bras Dermatol. 2017;92(3):345-49. 